\title{
Evolution Of Technology And Skills In Production Workplaces Utilizing Advanced TPS
}

Manabu Yamaji, (E-mail: yamaji@ise.aoyama.ac.jp), Aoyama Gakuin University Hirohisa Sakai, (E-mail: h_sakai@mail.toyota.co.jp), Toyota Motor Corporation Kakuro Amasaka, (E-mail: kakuro_amasaka@ise.aoyama.ac.jp), Aoyama Gakuin University

\begin{abstract}
The Japanese industrial companies demand changes. Simultaneous achievement of consistent quality worldwide, simultaneous startup and QCD (Quality, Cost and Delivery) is necessary to achieve successful global production. The authors think that evolution of technology and skill to realize a guarantee of high quality in production workplaces of production shop is necessary for a global production strategy. Therefore, in this paper, the authors focus on "intellectual working value" and propose the basic principle of intellectual working value improvement and the "Working Value Improvement Management Model". Furthermore the evolution of technology and skill realizing a high cycle of manufacturing technique in a Japanese offshore production factory was verified at Toyota Motor Corporation.
\end{abstract}

\section{INTRODUCTION}

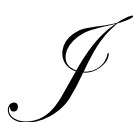

apanese industrial companies demand two changes. First, they have to reduce lead time for design, marketing and production, to adapt to sophisticated and diversified customer needs. Second, globalization of the production base must be realized to improve product quality. Simultaneous achievement of consistent quality worldwide, simultaneous startup and QCD (Quality, Cost and Delivery) is necessary to achieve successful global production. Realization of an advanced production system is demanded in order to offer a high value-added product to the customer. The authors think that evolution of technology and skills to realize a guarantee of high quality in production workplaces is necessary for a global production strategy.

Manufactures should shift from work-oriented shop designs to people-oriented shop designs that put more focus on the work environment [1][11][18]. As an example of manufacturing innovation in overseas countries, various governmental actions for older workers have been taken in Scandinavian countries that have aging workforces. Though the necessity of such actions has been advocated in Japan, actions have been relatively modest compared with that in Scandinavian countries [15][16]. At Toyota, improvements have been based mainly on the TVAL (ToyotaVerification Assembly Load) [17] for quantitative evaluation of workloads. These studies suggest a concrete methodology. However, there is no suggestion of a management model.

Therefore, in this paper, the authors focus on "intellectual working value" and propose the basic principle of intellectual working value improvement and the "Working Value Improvement Management Model". Furthermore the evolution of technology and skill realizing a high cycle of manufacturing technique in a Japanese offshore production factory was verified at Toyota.

\section{PROBLEMS IN PRODUCTION OF OVERSEAS FACTORY PRODUCTION}

The conventional Japanese manufacturing methods is to 1) educate a local person in Japan, and 2) send the person abroad after he/she has worked at solving problems in Japan. Was there originally a purpose to this? Current problems at overseas factories are i) dispersion of engineers and a decline in technology, ii) achieving consistent 
quality worldwide, and iii) global production. Current problems of management are quality control technology and personnel training.

The authors focus on "intellectual working value". The authors defined "intellectual working value" as "the performance and outcome of work" which improves the working value of field work. In turn, the worker is more willing to work at the company, permanently offers a product which the customer expects, and contributes to society. The authors think that "intellectual working value" is an important factor in quality management. The evolution of technology and skills is necessary to raise "intellectual working value".

\section{KEY TO GLOBAL PRODUCTION, STRATEGIC APPLICATIONS OF NEW JIT}

To win the global competition, big enterprises both in Japan and overseas are actively promoting global marketing that aims to achieve the consistent quality and production at optimal locations (simultaneous start-up) throughout the world. Manufacturing companies, in particular, are required to grasp customer needs and provide products responsibly to the market through global production without falling behind their competitors. So it is necessary to improve labor productivity and work value. In order to solve this problem, it is now necessary to establish a principle of new management technology for the next generation that will serve as a systematic and organizational behavioral principle to achieve a higher linkage of the business process cycles of all divisions, including not only sales, development, and design and manufacturing, but also indirect divisions such as administrative/clerical, and suppliers [5].

Based on these needs, the authors [2] proposed a new principle for next-generation management technologies - New JIT, as shown in Figure 1. The hardware systems of New JIT are TMS, TDS, and TPS. These core systems are indispensable for establishing new management technologies. Further, the authors [3][4] have proposed a new principle of quality management called Science TQM (Total Quality Management by Utilizing Science SQC called TQM-S) by using a principle of quality management, Science SQC (Statistical Quality Control), as a software system that improves the quality of all divisions' business processes in developing strategic quality management, important for survival in the current environment of worldwide quality competition.

Based on these, the authors [2][6] have been verifying the effectiveness of New JIT as a new management technology model to further develop traditional JIT [6][12] practices at an advanced company in Japan. An example of the above mentioned new strategy of New JIT as the key to success in global production is discussed in Chapter 4, focusing on workers engaging in direct line work - advancement of production sites indispensable for the strategic operation of TPS.

\section{ADVANCED TPS}

Recently, the author [1] referred to the effectiveness of TPS, applying Science SQC as a positive way of improving the quality of business processes in workshops, the sites at which Toyota's New JIT activities take place. TPS uses both IT and SQC in combination in order to produce generalizations about behavior patterns for practicing customer-oriented quality and production management that the production workshop or production engineering department builds into the processes.

The authors [15] considered the necessity of including and organically integrating these four elements with strategic application of the Advanced TPS (Figure 2) in view of global production, and clarified the New Japan Production Model, an advanced production management principle, as the global production technology and management model. The mission of the Advanced TPS in global deployment of New JIT is to realize CS (Customer Satisfaction), ES (Employee Satisfaction) and SS (Social Satisfaction) through production with high quality assurance.

In implementing New JIT for uniform quality worldwide and production at optimal locations, (i) renewal of production management system appropriate for digitized production and (ii) creating attractive workshop environments tailored to increasing numbers of older and female workers are the fundamental requirements. In more definite terms, (a) one is to strengthen the process capability maintenance and improvement by establishment of an 
intelligent quality control system. The second (b) is to establish a high-reliability production system for high quality assurance. The third (c) is reformation of the work environment for enhancement of intelligent productivity. The last (d) is to develop intelligent operators (skill level improvement) and to establish an intelligent production operating system.

The requisite for success is the execution of "Intellectual working: intelligent manufacturing floor". For any of these items, it could be said that the success of production is determined by the workers' "performance of intelligent work - upgrading the intelligence of production sites"

\section{EVOLUTION OF TECHNOLOGY AND SKILL}

Working value improvement is necessary to evoluve workers' technology and skill.The "working value" the authors have in mind here can be defined as, "the performance and outcome of work" brought about by onsite workers, which contributes to customer value. That is to say, the improvement in working value involves the creation of value of the onsite work by the workers themselves who also share the "sense of purpose in life" through mutual enlightenment received from team activities, and thus experience self-realization and self-development. In other words, such workers can find significance in working for their companies and contribute to society by continuously offering products that meet customer expectations.

\section{The Basic Principle Of Intellectual Working Value Improvement}

A priority issue in particular is the securing of working productivity at overseas plants deployed by advanced manufacturers promoting global production at a rapid rate. Against this background, the authors create and propose the "basic principle of working value improvement", as depicted in Figure 3, on the premise that a well-planned human resource development scheme aimed at improving worker motivation is a top issue from the standpoint of working value improvement.

Of the 5 layered levels in the Figure 3, (a) physical workload reduction, puts emphasis on the necessity of a practical program as well as implementation of the reduction of heavy labor work in continuous and tedious on-site operations with a view to realizing "error-free manufacturing" to meet customer expectations. [19]

Next, (b) mental workload reduction from the standpoint of securing process capability focuses on prioritizing the realization of a comfortable working environment in which the workers can fully demonstrate their skills.

In (c), self-actualization, worker morale improves by learning higher technology and skills.

So workers (d) contribute to an organization by utilizing those technologies and skills. More workers (e) contribute to social satisfaction and (f) customer satisfaction by producing high quality products.

\section{Intellectual Working Value Improvement Management Model}

Based on the suggested basic principle of working value, "Working Value Improvement Management Model" for improving working value is proposed as outlined in Figure 4.

QCD simultaneous achievement is indispensable for Japanese companies in order to respond to global production. So design, production, marketing, quality assurance, human resource development, and administration cooperate and must reform the technologies and skills of the workers. In particular, boosting morale, reduction of fatigue, development of physical strength, development of tools and devices, improvement of thermal environment and prevention of illness and injury are required for evolution. To practice these, the company must develop a network system to connect the entire company and CAE (Computer Aided Engineering) to provide efficiency. Worker skills and technologies improve by developing and utilizing these systems precisely. Customer/environment satisfaction is realized by continuing to produce high quality products and working value is improved. 


\section{TOYOTA'S APPLICATION EXAMPLES}

The authors present Toyota's application examples of workload reduction and renovating work environment utilizing $\mathrm{CAE}$ in an offshore production factory.

When Toyota build factories overseas for several years, Toyota adopts a digital factory. This digital factory simulates the work environment. Examination of the work environment is possible before building a factory using this simulation.

\section{Optimization Of Logistics}

In recent years in overseas factories, work-related accidents by workers engaged in distribution occur frequently. The ratio of temporary employees is rising for domestic factories, and this problem has become more pronounced. For example, truck stopping areas are small and tractors may protrude and interfere with the surrounding environment. Or parts cabbies come in contact with people in narrow routes. Because many countries have introduced legislation towards security in industry, companies have increased safety precautions and stepped up checks on work environments.

Therefore, optimizing distribution routes is an important matter. In the Figure 5, the authors digitized distribution and planned optimization by digital simulation. This simulation optimizes placement and ii) logistic route around i) the main body line so that iii) parts cabbies do not interfere with workers and facilities. The facilities were re-designed. Workers can prevent accidents and mental workloads of workers are reduced by realizing this.

\section{TPS-LAS}

The authers have established the TPS-LAS Model (Toyota Production System Layout Analysis Simulation) [13], which can effectively realize a higher quality production system in response to digitalized production and for the purpose of innovating high quality assurance and production preparation processes. This model has contributed to shorter-term cultivation of skilled workers as well as the simultaneous achievement of QCD.

The TPS-LAS Model is equipped with (i) Logistics Investigation Simulation [10] (-LIS), (ii) Digital Factory Simulation [7][9] (-DFS), and (iii) Workability Investigation Simulation [14] (-WIS) as a component for incorporating digital engineering, computer simulation, and a layout CAE system as shown in Figure 6. Specific layouts are designed by computer, and reductions in workload for on-site skilled workers, as well as the work layout for high productivity focusing on rhythmical work operations, are simulated to enable production preparation fitting actual work operations conducted on-site, contributing to quicker launch of overseas production plants.

The authors present the effectiveness of the application of TPS-LAS. The first core element TPS-LAS-DFS enabled the authors to accomplish an improvement in availability on the assembly line of eight percent on average. Finding out various interferences between the facilities and verifying the arrangement of them and redesigning the production process in the early stage, repeated work was reduced by half. The second TPS-LAS-WIS enabled the authors to verify the workload and the workability simultaneously in advance. The facilities were re-designed. The operator's standing position was changed, and they have achieved a demonstration of a $10 \%$ improvement in line availability. Furthermore, the number of temporary workers who voluntarily resign could be reduced by showing them a virtual scene of their future work environment and workload in advance before they are hired.

Regarding overtime work issues, the third TPS-LAS-LIS enabled the authors to predict the causes of overtime work and declines in the availability of the assembly line in process planning and the line drawing stage related the concurrent engineering. Therefore, the authors were able to discover an optimum number of buffers and transfer equipment and develop an optimum transfer route. As a result, they were able to reduce the amount of instances of one hour of overtime work. With Advanced TPS, the authors were able to achieve the same high productivity and quality at both domestic and overseas plants, and to reduce lead-time and overseas labor force support in global production processes throughout the world. The results of this study have been deployed in Toyota's global 
production strategy, with its effectiveness verified by the excellent reputation of recent Toyota vehicles for their reliability and common workability in Europe and the United States [8].

\section{CONCLUSIONS}

The authors have proposed the basic principle and application model for the next generation, intellectual working value improvement by means of the advanced application of the "Advanced TPS (Total Production System) Model", which strategically deploys the "TPS", a core technology of "New JIT". Working value improvement is necessary to evolve workers' technology and skills. Its validity was verified though an example case of application at an advanced automotive manufacturer, Toyota global production.

\section{REFERENCES}

1. Amasaka, K., et al., 2000, AWD6P/J Report of First Term Activity 1996-1999: Creation of $21^{\text {st }}$ Century Production Line in Which People Over 60's Can Work Vigorously, Toyota Motor Corporation, 1-91. (in Japanese)

2. Amasaka, K., 2002: New JIT, A New Management Technology Principle at Toyota, International Journal of Production Economics, 80:135-144.

3. Amasaka, K., 2003: Development of Science TQM, A New Principle of Quality Management, International Journal of Production Research, 42/17:3691-3706.

4. Amasaka, K., 2003: Proposal and Implementation of the "Science SQC" Quality Control Principle, International Journal of Mathematical and Computer Modeling, Vol.38 No.11-13, pp.1125-1136.

5. Amasaka, K., 2005: Advanced TDS - New Japan Development Design Model, Journal of the Society for Production Management, The $22^{\text {nd }}$ Annual Technical Conference, Nagoya: 111-114. (in Japanese)

6. Amasaka, K., 2005: New Japan Production Method, An Innovative Production Management Principle, Proc. of the $16^{\text {th }}$ Annual Conference of the Production and Operations Management Society, Michigan, Chicago IL: 1-22 (CD-ROM).

7. Byoungkyu, C., BUMCHUL, P., and HO, Y., R, 2004: Virtual Factory Simulator Framework for Line Prototyping, Journal of Advanced Manufacturing Systems, 3/1:5-20.

8. JD Power and Associates, 2004: http://www.jdpower.com/.

9. Kesavadas, T., and Ernzer, M., 2003: Design of an Interactive Virtual Factory Using Cell Formation Methodologies, Journal of Advanced Manufacturing Systems, 2/2:229-246.

10. Leo, J., V., Amos, H., C., and Jan O., 2004: Simulation-based Decision Support for Manufacturing System Life Cycle Management, Journal of Advanced Manufacturing Systems, Vol.3, No.2, pp.115-128.

11. Niemelä R, Rautio S, Hannula M, Reijula K. 2002: Work environment effects on labor productivity: an intervention study in a storage building, American Journal of Industrial Medicine, 42; 328-335.

12. Ohno, T., 1977: Toyota Production System, Diamond-sha. ISBN 4-478-46001-9 (in Japanese)

13. Sakai H.\& Amasaka K., 2005, Intelligence TPS, Key to Global Production Strategy Advanced Science TQM: TPS-LAS Model Using Process Layout CAE System at Toyota, International Journal of Production Economics, (decided to be published, 2006)

14. Steffen, S., Gunter S., and Siegmar, H., 2003: Distributed Manufacturing Simulation as an Enabling Technology for the Digital Factory, Journal of Advanced Manufacturing Systems, 2/1:111-126.

15. The Japan Machinery Federation and the Japan Society of Industrial Machinery Manufacturers research report, 1995: Advanced Technology Introduction in Machinery Industry, 82-114. (in Japanese)

16. The Japan Machinery Federation and the Japan Society of Industrial Machinery Manufacturers Research Report, 1995, Production System Model Considering Aged Workers, 1-2. (in Japanese)

17. Toyota Motor Corporation, Toyota Kyushu Corp., 1994: Development of a new automobile assembly line, Business Report awarded with Ohkouchi Prize, 1993 (40th), 377-381. (in Japanese)

18. Vecchio D, Sasco Jr A, Cann IC., 2003: Occupational risk in health care and research, American Journal of Industrial Medicine, 43;369-397.

19. Womack, J.P. and Jones, D., 1994: From Lean Production to the Lean Enterprise, Harvard Business Review, March-April: 93-103. 


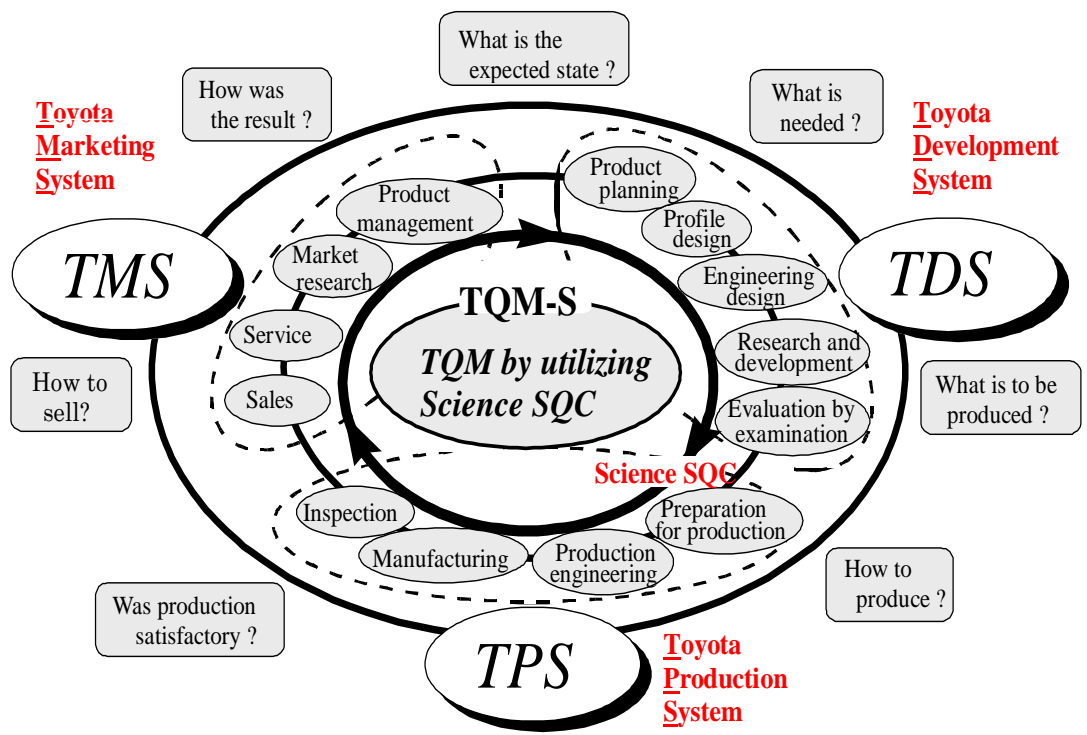

Figure 1: New JIT, Management Technology Strategy Model

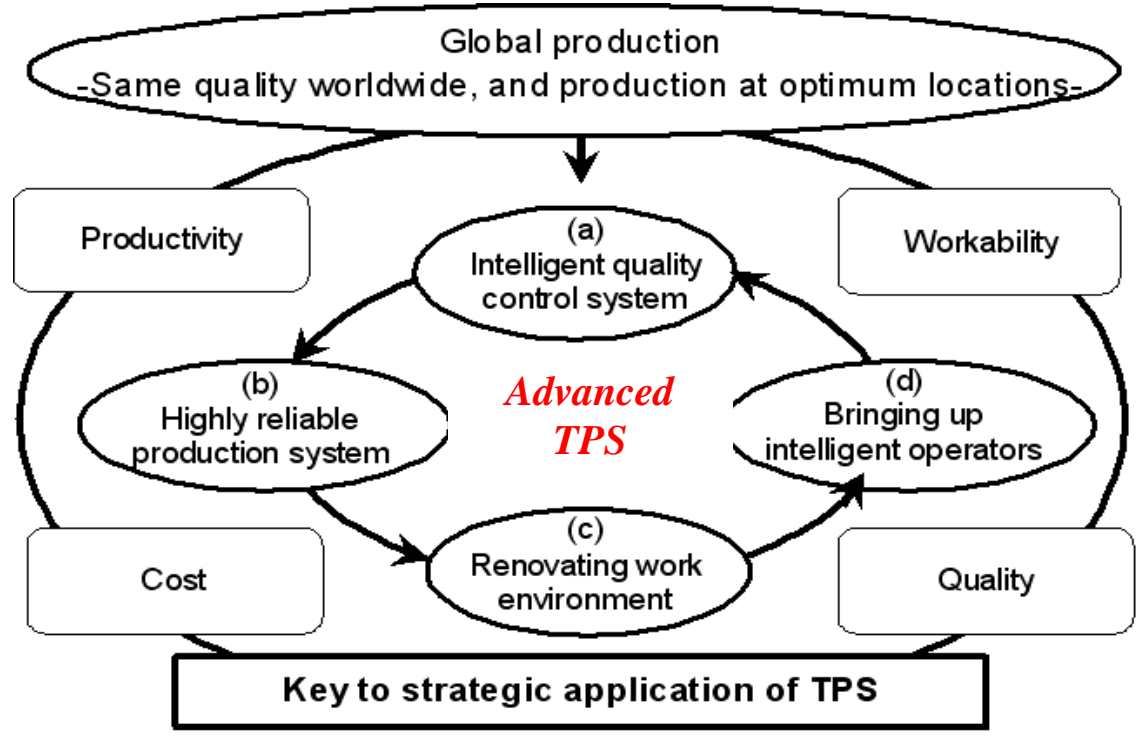

Figure 2: Schematic Drawing of Advanced TPS 